\title{
Vasoactive Intestinal Peptide maintains the non-pathogenic profile of human Th17-polarized cells
}

\author{
Rebeca Jimeno ${ }^{1}$, Javier Leceta ${ }^{1}$, Carmen Martínez ${ }^{2}$, Irene Gutiérrez-Cañas ${ }^{1}$, Mar Carrión ${ }^{1}$, \\ Selene Pérez-García ${ }^{1}$, Marina Garín ${ }^{3}$, Mario Mellado ${ }^{4}$, Rosa P. Gomariz ${ }^{1}$, Yasmina Juarranz ${ }^{1 *}$ \\ ${ }^{1}$ Departamento de Biología Celular, Facultad de Biología, Universidad Complutense de \\ Madrid, 28040 Madrid, Spain. \\ ${ }^{2}$ Departamento de Biología Celular, Facultad de Medicina, Universidad Complutense de \\ Madrid, 28040 Madrid, Spain. \\ ${ }^{3}$ División de Hematopoyesis y Terapia Génica, Centro de Investigaciones Energéticas, \\ Medioambientales y Tecnológicas, Madrid, Spain. \\ ${ }^{4}$ Departamento de Inmunología y Oncología. Centro Nacional de Biotecnología, Madrid, \\ Spain.
}

Rosa P. Gomariz and Yasmina Juarranz share senior authorship.

\author{
*Corresponding author: Yasmina Juarranz. Departamento de Biología Celular, Facultad de \\ Biología, Universidad Complutense de Madrid, 28040 Madrid, Spain. \\ Telephone number: 34913944971 \\ Fax number: 34913944981 \\ e-mail: yashina@bio.ucm.es
}

Running Tittle: VIP and human Th17 cell differentiation 


\begin{abstract}
The cytokine microenvironment modulates CD4 T cell differentiation causing the shift of naïve CD4 T cells into different cell subsets. This process is also regulated by modulators such as VIP, a neuropeptide with known immunomodulatory properties on CD4 T cells that exert this action through specific receptors, $\mathrm{VPAC}_{1}$ and $\mathrm{VPAC}_{2}$. Our results show that the pattern of VIP receptors expression ratio is modified during Th17 differentiation. In this report, we evaluate the capacity of VIP to modulate naïve human cells into Th17 cells in vitro by analyzing their functional phenotype. The presence of VIP maintains the non-pathogenic profile of Th17-polarized cells, increases the proliferation rate and decreases their Th1 potential. VIP induces the up-regulation of the STAT3 gene interaction with the VPAC 1 receptor during the onset of Th17 differentiation. Moreover, RORC, RORA and IL-17A genes are up-regulated in the presence of VIP through interaction with $\mathrm{VPAC}_{1}$ and $\mathrm{VPAC}_{2}$ receptors. Interestingly, VIP induces the expression of the IL-23R gene through interaction with the $\mathrm{VPAC}_{2}$ receptor during the expansion phase. This is the first report that describes the differentiation of naïve human T cells to Th17-polarized cells in the presence of VIP and demonstrates how this differentiation regulates the expression of the VIP receptors.
\end{abstract}

Keyword: Th differentiation, Th17, VIP, VPAC receptors. 


\section{Introduction}

The cytokine microenvironment and antigen-presenting cells drive in vivo differentiation and clonal expansion of naïve helper T cells, converting them to different effector cells with specific roles. Naïve human CD4 T cells can be committed to four major cells lineages, namely Th1, Th2, Th17 and induced regulatory T cells, on the basis of their cytokine and transcription factor (master regulator) signature (Zhu, 2010). The cytokine signature profile of Th17 cells is formed by several cytokines such as IL-17A, IL-17F, IL-21 and IL-22. Th17 cells are also characterized by the expression of chemokine receptors such as CCR6 and cytokine receptors such as IL-23R and IL-21R. Moreover, Th17 cells can secrete to a lesser extent IFNY, IL-10, IL-9, IL-2 and other cytokines. The final effector functions of Th17 cells depend on the specific combination of the cytokines produced (Zhu, 2008; Korn, 2009; Zhu, 2010; Ghoreschi, 2011; Hirota, 2012). Increasing evidence points to a heterogeneous and inherent phenotypic instability in this subset (Ghoreschi, 2011; Hirota, 2012; Sundrud, 2013). Th17 cells are susceptible to changing to Th1, most likely due to epigenetic regulation (Murphy, 2010; O’Shea, 2010; Zhu, 2010; Hirota, 2012).

The inflammatory microenvironment causes Th17 cells a separate Th subset with a homeostatic role, able to clear pathogens that are less efficiently resolved by Th1 or Th2 (Chen, 2008; Acosta-Rodriguez, 2007; Cua, 2010). In contrast, Th17 cells have also been related to organ-specific autoimmune diseases (Korn, 2009; Hirota, 2012; Marwaha, 2012). In order to understand the potential role of Th17 cells in the development of massive inflammation and autoimmune diseases, it is important to know the regulatory mechanisms involved in their differentiation, proliferation and function. Inhibitory cytokines, nuclear receptors, metabolic sensors, inhibitors of STATs, microRNAs (Hirahara, 2010; Bi, 2012; 
Hirota, 2012) and probably immunomodulatory neuropeptides, are able to modulate Th17 cells.

Vasoactive Intestinal Peptide (VIP) is a ubiquitous neuropeptide that plays important regulatory roles in many physiological processes through binding to its specific receptors, VPAC $_{1}$ and VPAC $_{2}$ (Couvineau, 2012; Harmar, 2012). In the immune system, VIP can modulate both innate and adaptive immunity, showing predominantly anti-inflammatory and immunomodulatory actions. In vivo mouse data indicate that VIP treatment may have a promising role in the treatment of inflammatory and autoimmune diseases (Delgado, 2001; Gomariz, 2006; Lodde, 2006; Arranz, 2008; Calafat, 2009; Smalley, 2009; Gomariz, 2010). In several animal models of inflammation and autoimmune diseases, it has been described that VIP decreases cytokine expressions related to Th17 cells (Abad, 2005; Leceta, 2007; Jimeno, 2010). However, in vitro studies using mouse $C D 4^{+} \mathrm{T}$ cells have reported that VIP plus TGF $\beta$ promote their differentiation to a Th17 subset in a VPAC 1 dependent manner (Yadav, 2008). Thus far, the role of VIP in human Th17 cells remains unclear.

Th17 cells are considered a major link between innate and adaptive immune responses, having a critical role in normal host defense (Graeber, 2012). This important scenery demands a better understanding of how these cells work and how they may be modulated by the microenvironment in a normal host and within the framework of autoimmune disease. Given the multiple effects of VIP on immune microenvironments and its immunomodulatory role in human autoimmune diseases, it is important to better understand the influence of VIP during human Th17 cell differentiation. This is the first report that maps the cytokine and master regulator pattern of the Th17 subset after its differentiation from naïve human CD4 T cells under the influence of VIP, examining their functionality and describing how VPAC receptors are modulated during Th17 differentiation. 


\section{Materials and Methods}

\section{Isolation of naïve human T cells}

Naïve $\mathrm{CD}^{+} \mathrm{T}$ cells were isolated from the human cord blood from six healthy donors. The study was performed according to the recommendations of the Declaration of Helsinki. The samples were obtained after the donors had signed a written informed consent and were approved by the ethics committee of the Transfusion Center (Comunidad de Madrid). For $\mathrm{CD}^{+} \mathrm{T}$ cells isolation, density gradient centrifugation by Ficoll-Hypaque (Sigma Aldrich) and negative selection using a commercial isolation system (RosetteSep ${ }^{\circledR}$ Human $\mathrm{CD}^{+}{ }^{\mathrm{T}}$ Cell Enrichment Cocktail from StemCell Technologies) were combined. Naïve T cells were then positively isolated with a MACS Cell Isolation kit using CD45RA $^{+}$MicroBeads (Miltenyi Biotec). The purity exceeded $90 \%$.

\section{In vitro Th17 cell polarization}

Cells were cultured at $4 \times 10^{4}$ cells/well in RPMI 1640 GlutaMAX media (Life Technologies) supplemented with $10 \%$ fetal bovine serum (Lonza) and $1 \%$ penicillin/streptomycin (Life Technologies). Cells were expanded with anti-CD3 and antiCD28 coated beads (Life Technologies). Three types of cultures were established: Nonpolarizing conditions; Th17-polarizing conditions in the presence of human recombinant TGFß (2ng/ml) (eBioscience), human recombinant IL-23 (10ng/ml) (eBioscience), human recombinant IL-6 (10ng/ml) (eBioscience), human recombinant $\mathrm{IL}-1 \beta \quad(10 \mathrm{ng} / \mathrm{ml})$

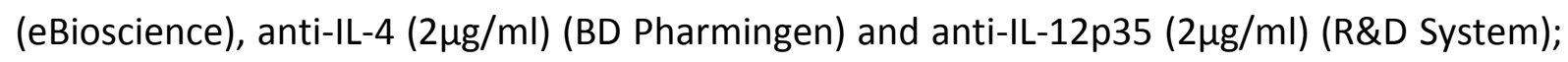
and VIP/Th17-polarizing conditions as above plus 10nM of VIP (Polypeptide Group). For

VPAC receptor agonist and antagonist studies, $10 \mathrm{nM}$ of agonist $\mathrm{VPAC}_{1}\left[\mathrm{~K}^{15} \mathrm{R}^{16} \mathrm{~L}^{27} \mathrm{VIP}(1-\right.$ 
7)/GRF (8-27)] or agonist VPAC 2 (RO 25-1553) were added instead of VIP; $1 \mu \mathrm{M}$ of $\mathrm{VPAC}_{1}$ antagonist [AcHis ${ }^{1}$ DPhe ${ }^{2} K^{15} R^{16} L^{27}$ VIP (3-7)/GRF (8-27)] was added in addition to VIP. On day 4 of culture, medium was replaced with one containing the recombinant cytokines, peptides and antibodies corresponding to each treatment but without anti-CD3 and anti-CD28 to avoid overstimulation.

\section{RNA Extraction and Semi-quantitative real-time PCR}

For total RNA extraction we used the TriReagent method (Sigma Aldrich). Total RNA $(2 \mu \mathrm{g})$ was reverse transcribed using a High Capacity cDNA Reverse Transcription Kit (Life Technologies). Semi-quantitative real-time Polymerase Chain Reaction (PCR) analysis for all molecules tested was performed using TaqMan Gene Expression Master Mix (Life Technologies), with the exception of IL-22, which was tested using SYBR ${ }^{\circledR}$ Green PCR Master Mix (Life Technologies) (Table 1). $\beta$-Actin was used as an endogenous reference gene. For each sample, we compared the amount of target mRNA normalized to the endogenous reference, using the formula $2^{-\Delta \Delta c t}$.

\section{Measurement of Cytokines}

Cells were restimulated on day 7 with $20 \mathrm{ng} / \mathrm{ml}$ Phorbol Myristate Acetate (PMA) and $0.5 \mu \mathrm{M}$ ionomycin (Sigma Aldrich) for 6 hours. After stimulation, the levels of IL-17A, IL-21, IL22, IFNY, IL-9, IL-2 (eBioscience) and IL-10 (Diaclone) were analyzed by Enzyme-Linked ImmunoSorbent Assay (ELISA).

\section{Measurement of BrdU incorporation}

Cell proliferation was determined by incorporation of Bromodeoxyuridine (BrdU) into DNA using the Cell Proliferation Assay Kit (Roche). On days 4 and 7 of culture, cells were 
incubated with $10 \mu \mathrm{M}$ BrdU for $24 \mathrm{~h}$. Absorbance at $450 \mathrm{~nm}$ with a $690 \mathrm{~nm}$ reference was measured in a plate reader (UVM 340 microplate reader, ASYS HITECH GMBH).

\section{Measurement of cell viability}

Viability of cells was determined by trypan blue dye exclusion assay. On day 7 of culture, cells were collected and incubated with trypan blue solution (1:1) and the number of viable and dead cells was counted. Cell viability was calculated as the relationship between the number of viable cells on day 7 and the total number of cells cultured.

\section{Flow cytometry analysis}

After seven days of culture, cells were collected from the culture plates and labelled with phycoerythrin-conjugated CCR6 (clon 11A9, BD Pharmingen) at 4을 for 30 minutes. Cells were washed, fixed and permeabilized with Transcription Factor Buffer Set (BD Pharmingen) for 50 minutes at 4 으. Then, cells were labelled with Alexa Fluor 488conjugated T-bet (O4-46, BD Pharmingen), allophycocyanin-conjugated RORC (clone AFKJS-9, eBioscience) and Brilliant Violet 711-conjugated Ki67 (clone Ki-67, BioLegend) at 4으 for 1 hour in perm/wash buffer. Auto-fluorescence and isotype controls were set up to define non-specific fluorescence.

\section{Immunocytochemistry Staining}

On days 0 and 7 , cell suspensions were centrifuged onto glass slides $(50.000$ cells/glass slide), dried and fixed. Cells were then rehydrated and blocked with PBS containing $5 \%$ goat serum and $5 \%$ donkey serum. After washing, cells were incubated with $0.02 \mathrm{mg} / \mathrm{mL}$ rabbit anti-VPAC 1 polyclonal antibody and/or mouse anti-VPAC $\mathrm{C}_{2}$ monoclonal antibody (Acris Antibodies) for 1 hour. After washing, cells were incubated for 45 minutes 
with $1 \mu \mathrm{g} / \mathrm{mL}$ Donkey anti-rabbit IgG $(\mathrm{H}+\mathrm{L})$ Alexa Fluor 488-conjugated and goat anti-mouse $\operatorname{lgG}(\mathrm{H}+\mathrm{L})$ Alexa Fluor 594-conjugated (Life Technologies). Cells were counterstained with $1 \mu \mathrm{g} / \mathrm{ml}$ Hoechst to visualize nuclear bodies.

\section{Statistical Analysis}

The $t$ test was used to compare different cell populations, and correlations were conducted using Pearson's coefficient test. Both statistical tests were done using GraphPad Prism Version 4.0 software (GradphPad Software).

\section{Results}

\section{In vitro differentiation of Th17 cells and its maintenance by VIP}

First, we analysed the features of differentiated Th17 cells by checking protein expression of different cytokines in the supernatants after seven days of culture (Fig. 1A). Signature cytokines of the Th17 subset such as IL-17A or IL-21 were significantly increased in the supernatants of Th17-polarized cells. Surprisingly, the Th17-polarized cells secreted significantly less IL-22 compared to non-polarized cells. IFNy levels in supernatants of Th17polarized cells were lower with respect to non-polarized cells. Analysis of IL-2 and IL-10 production showed no clear differences between Th17-polarized and non-polarized cells. Finally, IL-9 determination showed higher protein levels in Th17-polarized cells than in the non-polarized cells. Thus, Th17-polarized cells in this in vitro system are characterized by high expression levels of IL-17A, IL-21 and IL-9 and low levels of IFNY and IL-22. Cytokine levels in VIP/Th17-polarized cells were similar to Th17-polarized cells, with the exception of IL-17A protein, which was lower in the Th17-polarized cells in the presence of VIP. Nevertheless, IL-17A levels were significantly higher in these cells than in non-polarized cells. 
We analyzed the mRNA expression of IL-21R, IL-23R and IL-12Rß2 (Fig. 1B). Regarding IL-21R expression, similar levels of expression were determined in all cases. Our data also showed higher IL-23R mRNA levels in Th17-polarized cells compared to non-polarized cells. VIP significantly increased the expression of IL-23R. IL-12 receptor expression was determined by the analysis of the IL-12R 32 subunit. The results showed significantly decreased IL-12R 32 expression in both Th17- and VIP/Th17-polarized cells.

We also examined the mRNA expression of transcription factors of different Th subsets (Fig. 2). Results showed that RAR-related Orphan Receptor C (RORC), RORA and Aryl hydrocarbon Receptor (AhR) expression were higher in Th17-polarized than in non-polarized cells. Analysis of STAT3 expression did not show significant differences between the two conditions. In contrast, Foxp3 and T-box transcription factor (Tbx21/T-bet) expression was lower in Th17-polarized than non-polarized cells. Interestingly, VIP/Th17-polarized cells showed higher RORC, RORA and STAT3 expression than Th17-polarized cells. In summary, the presence of VIP during human Th17 differentiation could maintain their Th17 commitment and significantly enhances IL-23R, RORC, RORA and STAT3 expression.

\section{Functional features of in vitro human Th17-polarized cells: Modulation by VIP}

Recent studies have begun to shed light on the heterogeneity (pathogenic or nonpathogenic phenotype) and inherent phenotypic instability of Th17 subsets (McGeachy, 2007; Murphy, 2010; Sundrud, 2013). Different profiles of cytokines expressed by Th17 cells are related to the pathogenic or non-pathogenic phenotype of these cells, thus we determined the correlations between several cytokines, associated with pro-inflammatory or anti-inflammatory Th17 profiles, with IL-17 and RORC (Fig. 3). IL-17A levels were positively correlated with IL-10, IL-9 and IL-21 levels, either in the presence or absence of VIP, with a 
Pearson's coefficient $(r)$ near 1.0 in all cases. Negative correlations were seen between IL-2 and IL-17A and between RORC and IL-22 (Pearson's coefficient close to -1) in both cases. On the other hand, considering the balance of Th17/Th1, only when VIP is added to the cultures, IFNY and Tbx21 expressions were negatively correlated to the expression of IL-17A and RORC, respectively (Fig. 4A). Flow cytometric analysis of RORC- and T-bet-expressing cells on day 7 showed that $78.8 \%$ and $81.7 \%$ of Th17- and VIP/Th17-polarized cells, respectively, were positive for RORC but negative for T-bet (Fig. 4B). A small percentage of RORC ${ }^{+} /$T-bet $^{+}$ double positive cells was detected, which was lower in VIP/Th17-polarized $(1,87 \%)$ than in Th17-polarized cells (3,85\%).

Functional features of Th cells depend on their proliferation and homing capacity. Hence, we also tested their proliferation rate by analysing the incorporation of BrdU into DNA on days 4 and 7 (Fig. 5A). There were no significant differences between Th17- and VIP/Th17-polarized cells on day 4, whereas on day 7 Th17-polarized cells had higher levels of BrdU incorporation than non-polarized cells. Interestingly, at day 7 , the presence of VIP during the Th17 polarization of the naïve Th cells increased their proliferation rate compared to non-polarized and Th17-polarized cells. Also, we determined the cell viability of our cells on day 7. No differences were found in the cell viability between non-polarized cells and Th17-polarized cells, and between Th17-polarized cells and VIP/Th17-polarized cells (Fig.5A). In addition, we measured the proportion of cells that expressed RORC and the proliferation marker Antigen KI-67 (Ki67) by flow cytometric analysis (Fig. 5B). Around 83\% of total cells were double positive for RORC and Ki67. Almost all RORC cells were actively proliferating. No differences were observed when VIP was added to the cultures. 
We explored the homing capacity of the Th17 cells by studying the expression of the chemokine receptor CCR6. Double positive RORC/CCR6 cells were detected on Th17polarized (74.8\%) and in VIP/Th17-polarized cells (77.3\%) (Fig. 5C) indicating that Th17polarized cells have a migration capacity and that VIP preserves their homing capacity.

\section{Switch in the expression pattern of VIP receptors with Th17 polarization}

We tested the expression of $\mathrm{VPAC}_{1}$ and $\mathrm{VPAC}_{2}$ receptors for VIP. As Fig. 6A shows, $\mathrm{VPAC}_{1}$ expression is down-regulated during $\mathrm{T}$ cell culture under CD3 and CD28 stimulation whereas $\mathrm{VPAC}_{2}$ expression is maintained with Th17 polarization. The ratio between mRNA expression of $\mathrm{VPAC}_{2}$ and $\mathrm{VPAC}_{1}$ receptors was significantly increased in activated/expanded cells with respect to $C D 4^{+} \mathrm{CD} 45 \mathrm{RA} \mathrm{A}^{+}$T cells after seven days of culture. This ratio was close to 1.0 in non-polarized cells; however, it was significantly increased in Th17- and VIP/Th17polarized cells. VIP/Th17-polarized cells increased the expression of both receptors but not significantly. The $\mathrm{VPAC}_{1}$ increase in VIP/Th17-polarized cells was of greater magnitude compared to the $\mathrm{VPAC}_{2}$ increase; consequently the $\mathrm{VPAC}_{2} / \mathrm{VPAC}_{1}$ ratio was significantly less than in Th17-polarized cells. VPAC receptor expression was corroborated at the protein level by immunocytochemical analysis (Fig. 6B). We detected expression of both $\mathrm{VPAC}_{1}$ and $\mathrm{VPAC}_{2}$ in naïve Th cells and Th17-polarized cells. No staining was observed when isotype controls were used. These results confirmed the receptor pattern observed at the mRNA level. In summary, $\mathrm{VPAC}_{1}$ could be the main receptor involved during the onset of Th17 generation, whereas Th17 differentiation induces a switch on VIP receptors, with $\mathrm{VPAC}_{2}$ being the main receptor expressed after the differentiation of Th17 cells.

In order to test the specificity of VPAC receptor involvement in the effect of VIP during Th17-polarization, we used specific agonists and one antagonist (Fig. 7). The presence 
of $\mathrm{VPAC}_{1}$ antagonist during the differentiation of VIP/Th17 cells significantly reduced IL-17A, STAT3 and RORC VIP-stimulated mRNA expression. RORA was also reduced but not significantly. In Th17-polarized cells, the VPAC $_{1}$ agonist significantly augmented IL-17A, RORC, RORA and STAT3 mRNA expression compared to Th17-polarized cells. In Th17polarized cells, the $\mathrm{VPAC}_{2}$ agonist induced an increase in the expression of mRNA in all molecules tested with the exception of STAT3.

\section{Discussion}

Th17 cells were initially described as the key pathogenic element in several autoimmune diseases (Korn, 2009; Hirota, 2012; Marwaha, 2012). Conversely, new evidence suggests that, depending on the microenvironment, Th17 cells can alter their differentiation program, inducing either protective/anti-inflammatory or pro-inflammatory responses (Ghoreschi, 2011; Marwaha, 2012; Sundrud, 2013). How different factors of an inflammatory microenvironment can modulate differentiation, function or pathogenicity of human Th17 is still unclear and requires further attention. Given the known immunomodulatory and antiinflammatory role of VIP in several inflammatory and autoimmune disorders, we report for the first time the influence of this neuropeptide on human Th17 cell differentiation and function.

Many studies have examined Th17 differentiation in vitro, both in mouse and human. Although there are discrepancies between different authors about the importance of some cytokines, it is clear that IL-6, IL1- $\beta$ and IL-21 are involved in human Th17 differentiation (Korn, 2009; Ganjalikhani, 2011; Hirota, 2012). The implication of TGF $\beta$ in this process is associated with the pathogenicity, or lack thereof, of Th17 cells. This cytokine is linked with the differentiation of a non-pathogenic phenotype (McGeachy, 2007; Ghoreschi, 2011; 
Zuñiga, 2013). Despite its implications in their potential pathogenicity (Lee, 2012), the presence of IL-23 is necessary for the stabilization of Th17 cells (Korn, 2009). In this sense, McGeachy et al. suggest that when cells are polarized in the presence of TGF $\beta$, IL-6 and IL23 , the effect of the former are predominant with respect to IL-23 and this effect is related with a non-pathogenic phenotype (McGeachy, 2007). For these reasons, we used IL-6, IL1- $\beta$, IL-21, TGF $\beta$ and IL-23 in our in vitro human Th17 differentiation model.

As expected, a main increase in IL-17A and IL-21 cytokines and the transcription factors RORC and RORA were confirmed in Th17-polarized cells. Indeed, a positive correlation between IL-21 and IL-17A was observed. In contrast, a decrease in IL-22 levels was detected in Th17-polarized cells. A negative correlation between IL-22 and RORC was observed in Th17-polarized cells. In accordance with these findings, it has been described that T cells re-stimulated in the presence of TGF $\beta$ and IL- 6 did not induce IL-22 expression (McGeachy, 2007). Related to IL-2 expression, results showed a slight tendency to decrease IL-2 secretion and a negative correlation between IL-2 and IL-17 in Th17-polarized cells. IL-2, a survival factor of Th cells, inhibits Th17 differentiation at early stages, but can expand Th17 cells at a late stage (Amadi-Obi, 2007; Korn, 2009). Their high expression levels in Th17 cells have been associated with a pathogenic phenotype in these cells (Gohreschi, 2011; Zuñiga, 2013). Meanwhile, similar levels of IL-10 were detected in non-polarized and Th17-polarized cells. In contrast, the IL-9 levels were increased in Th17-polarized cells. A positive correlation between IL-10 and IL-17 and between IL-9 and IL-17 levels appears in Th17-polarized cells. The production of IL-10 and IL-9 by Th17 cells points to their potential non-pathogenic/antiinflammatory phenotype (Gohreschi, 2011; Zuñiga, 2013). In this sense, Th17 cells activated in the presence of TGF $\beta$ and IL- 6 secrete IL-17 and IL-10, suggesting a potential regulatory function for these cells or a possible regulatory mechanism to counteract their pathogenic 
potential (McGeachy, 2007). In addition, it has been demonstrated that IL-9 non-secreting Th17 cells were more pathogenic than IL-9 secreting Th17 cells (Beriou, 2010). In regards to the cytokine receptor, we observed higher IL-23R mRNA levels in Th17-polarized cells than in non-polarized cells. Therefore, Th17-polarized cells are able to respond to IL-23, the cytokine necessary for the stabilization of this subset. Different reports relate IL-23R expression to the pathogenicity of Th17 cells (Lee, 2012; Zuñiga, 2013). However, this receptor is not exclusive of pathogenic Th17 cells, but the overexpression of IL-23R is related to a pathogenic/proinflammatory phenotype (Ghoreschi, 2011; Lee, 2012; Zuñiga, 2013). Aside from RORC and RORA, another transcription factor closely related to the Th17 subset is AhR. As has been previously described, AhR expression was significantly increased in Th17-polarized cells (Veldhoen, 2008). Ghoreschi, et al. showed that Th17 cells, differentiated in the presence of TGF $\beta$, express high levels of AhR and demonstrated that these cells are less pathogenic than Th17 cells differentiated in the absence of TGF $\beta$ that do not express AhR (Ghoreschi, 2011). Taking into account all of these data, our data show that Th17 cells differentiated in our culture conditions present the following characteristics of a non-pathogenic/antiinflammatory profile: an increase in IL-9 secretion, AhR expression and a decrease in IL-22 and IFN $\gamma$ secretion and T-bet expression. In addition, we demonstrated positive correlations between IL-17 and cytokines related to non-pathogenic phenotype (IL-17 and IL-10, IL-17 and IL-9) and a negative correlation with pathogenic indicators (IL-17 and IL-2, RORC and IL22).

From the standpoint of plasticity and heterogeneity, Th17 cells are closely related to the Th1 subset (Murphy, 2010; O'Shea, 2010). The levels of IFNY and Tbx21 were decreased in Th17-polarized cells. It has been suggested that TGF $\beta$ downregulates Tbx21 expression and as a consequence IFN $\gamma$ expression (Ghoreschi, 2011; Zuñiga, 2013), decreasing IFN $\gamma^{+} /$IL- 
$17^{+}$double-secreting Th17 cells (Ganjalikhani, 2011). A low percentage of RORC $^{+} /$T-bet $^{+}$ double-positive cells was observed in our cultures. Moreover, IL-12Rß2 expression was significantly decreased after Th17-differentiation, in agreement with previous reports (Korn, 2009). On the basis of all of these findings, we document a decrease in Th1 profile of Th17 cells polarized in these in vitro conditions. This fact is related with a non-pathogenic/antiinflammatory phenotype, since conversion of Th17 to a Th1 phenotype can promote the pathogenic potential of these cells.

Proliferation analysis showed a greater proliferation in Th17-polarized cells than in non-polarized cells on day 7 . In addition, we confirmed that around $83 \%$ of total cells were double positive for RORC and Ki67. Therefore, in our culture conditions, almost all RORC cells were actively proliferating. Although it has been described that Th17 cells have a low ability to proliferate and to produce IL-2 in response to combined CD3 and CD28 stimulation (Santarlasc, 2012), Th17 cells polarized in our cultures show high proliferation rate and secreted IL-2. This fact could be explained in part by the increase in the expression of IL-23R during differentiation process and their capacity to answer to IL-23, cytokine associated with the expansion of Th17 subset (Zhu, 2008). In addition, differences in culture conditions such as the stimulation conditions, the cytokines used in the polarization, the time of the culture or the method used to check the proliferation, could explain this discrepancy.

In addition to previous analyses, we checked the homing capacity of the Th17 cells through the analysis of the expression of the chemokine receptor CCR6, which is the most important homing receptor for Th17 cells. This chemokine receptor allows their migration to an inflammatory microenvironment in response to CCL20 (Acosta-Rodriguez, 2007; Korn, 2009). Double-positive RORC/CCR6 cells were detected in Th17-polarized cells. These results 
indicate that Th17 cells polarized in our in vitro culture conditions have the capacity of respond to CCL20.

VIP plays several modulatory roles in many physiological processes in the immune system. It shows predominantly anti-inflammatory and immunomodulatory actions, modulating the innate and the adaptive responses. Related to Th subsets, it has been described that VIP is able to modulate Th1, Th2 or iTreg cells (Gomariz, 2006; GutiérrezCañas, 2008; Jimeno, 2010; Jimeno, 2011). In vitro and ex vivo studies with mice demonstrated that VIP can promote the Th17 subset, over the Th1 subset (Yadav, 2008; Jimeno, 2011). Our results show that in human VIP/Th17-polarized cells the IL-17A secretion was decreased. This decrease in IL-17A protein expression in the presence of VIP has been described previously (Jimeno, 2011). However, results show that VIP induces the expression of IL-17A mRNA levels. Post-transcriptional regulation mechanisms could be involved in this discrepancy, but future studies are needed to clarify this. Related to cytokine receptor expression, IL-23R mRNA expression was increased in the presence of VIP. As mentioned above, the expression of IL-23R indicates that cells are able to respond to IL-23, the cytokine necessary for the stabilization of this subset. Although several reports have associated the overexpression of IL-23R with pathogenicity of Th17 cells (Ghoreschi, 2011; Lee, 2012; Zuñiga, 2013), the expression of IL-23R is not exclusive of pathogenic Th17 cells. In this sense, the increase in IL-23R expression shown in the presence of VIP could indicate a greater stabilization of Th17-polarized cells generated in these culture conditions. On the other hand, our results show that RORC, RORA and STAT3 were significantly increased in the presence of VIP. Since the lineage-defining transcription factors of the Th17 cells are RORC and RORA (Yang, 2008), the increase in expression of both in the presence of VIP show that this neuropeptide promotes Th17 differentiation in our culture conditions. In addition, it has 
been described that STAT3 is related to IL-23R, RORC and RORA expression (Harmar, 2012). For this reason, an increase in STAT3 expression in cells treated with VIP could indicate that VIP supports Th17 cells. On the other hand, in the presence of VIP, no differences in the expression of IL-22 were detected in the Th17-polarized cells, but were significantly less expressed than in non-polarized cells. In this sense, it has been reported that VIP decreases IL-22 production by Th17 cells (Ding, 2012) but, conversely, increases IL-22 expression during mouse Th17 differentiation (Yadav, 2008). Regarding the heterogeneity of Th17 cells, it has been described that VIP promotes Th17 over the Th1 subset in mouse (Jimeno, 2011) and in a model of autoimmune diabetes (Jimeno, 2010). A positive correlation between IFNY and IL17A and between Tbx21 and RORC was observed in Th17-polarized cells. This may indicate a slight tendency toward a Th1 shift in the present culture conditions. Recent studies highlight the importance of the plasticity of Th17 cells in the Th1 phenotype (Lee, 2008; Lexberg, 2010; Hirota, 2012; Sundrud, 2013). Conversion of Th17 to the Th1 phenotype might contribute to the pathogenic potential of these cells. Analysis of the Th17/Th1 profile in the presence of VIP showed that these correlations were negative in VIP/Th17-polarized cells, which also show a decrease in $\mathrm{RORC}^{+} / \mathrm{T}^{- \text {bet }^{+}}$double-positive cells, indicating that in the presence of VIP, Th17 cells are less prone to differentiate to a Th1 pathogenic phenotype (Fig.8).

It has been shown that VIP inhibits proliferation of human $\mathrm{CD}^{+} \mathrm{T}$ cells and mouse erythrocyte-depleted spleen cells (Delgado, 1996; Jimeno, 2011). However, in human, VIP can act as an inductor or inhibitor of proliferation in different human cells (Harmar, 2012). Our results using BrdU indicate that VIP promotes the proliferation rate of Th17-polarized cells at day 7 . Moreover, we determined the cell viability on day 7 and found no differences between Th17-polarized cells and VIP/Th17-polarized cells. Thus, we confirmed that the VIP 
effect was due to a proliferation increase and not a cell viability increase. On the other hand, presence of VIP is not altered. This is not unexpected since BrdU is incorporated into DNA only during the $\mathrm{S}$ phase of the mitotic process whereas Ki67 is expressed for its whole duration. Therefore, a possible effect of VIP only during the S phase could be lost in Ki67 expression analyses given the high expression levels of this protein in Th17-polarized cells. In summary, the presence the VIP caused an increase in the proliferation rate of Th17-polarized cells (Fig. 8). This result is according to above mentioned results and they indicate that VIP promotes the Th17 population in our culture conditions. These findings are consistent with previous in vitro and ex vivo studies in mice that demonstrated that VIP can promote the Th17 subset (Yadav, 2008; Jimeno, 2011). In addition, studies with different mice models of autoimmune diseases have shown that VIP is able to promote the Th17 differentiation in vivo (Abad, 2005; Leceta, 2007). Taking account, that there are endogenous sources of VIP, as nerves fibres and immune cells, this neuropeptides could modify human Th17 profile in vivo.

In relation to VIP receptor expressions, $\mathrm{CD}^{+} \mathrm{T}$ cells have been studied previously (Vomhof-DeKrey, 2008; Dorsam, 2011). Our results demonstrate the interesting finding that the VPAC receptor pattern changed in our cultures. Unlike naïve Th cells, Th17-polarized cells predominantly express the $\mathrm{VPAC}_{2}$ receptor. It has been described that naïve human and mouse $\mathrm{CD}^{+} \mathrm{T}$ cells predominantly express the $\mathrm{VPAC}_{1}$ receptor and after clonal expansion there is a down-regulation of this receptor (Vomhof-Dekrey, 2008; Dorsam, 2011). Changes in the pattern of VIP receptors with the degree of activation/maturation of the cells have been described (Juarranz, 2008; Vomhof-Dekrey, 2008; Dorsam, 2011). Although an increase in the $\mathrm{VPAC}_{2} / \mathrm{VPAC}_{1}$ ratio was observed in non-conditioned cells, this increase was 
significantly higher in Th17-polarized cells. In addition, Yadav et al. noted that VIP-induced Th17 differentiation was mainly mediated through the $\mathrm{VPAC}_{1}$ receptor (Yadav, 2008). In addition, in our cultures, the high levels of $\mathrm{VPAC}_{1}$ expression in naïve cells may be involved in the differentiation process. Differential expression of VIP receptors in human Th cells is poorly understood and future studies are needed to clarify whether Th17-polarized cells express more VPAC 2 or VPAC 1 . On the other hand, we tested the specificity of VIP receptors involvement in the effect of VIP during Th17-polarization using specific agonists and antagonist (Fig. 8). The specific agonists for $\mathrm{VPAC}_{1}$ and $\mathrm{VPAC}_{2}$ were previously and extensively used with a high affinity for each receptor subtype (Couvineau, 2012; Harmar, 2012). The specific VPAC 1 antagonist, $\left[\right.$ AcHis $\left.^{1} \mathrm{DPhe}^{2} \mathrm{~K}^{15} \mathrm{R}^{16} \mathrm{~L}^{27} \mathrm{VIP}(3-7) / G R F(8-27)\right]$, has 200 to 1000-fold greater affinity for the human $\mathrm{VPAC}_{1}$ than for the human $\mathrm{VPAC}_{2}$ receptor. However, it does not stimulate the adenylate cyclase activity of any membrane preparation in a concentration range from 0.1 to $10.000 \mathrm{nM}$ (Gourlet, 1997; Ceraudo, 2012). As a consequence, this antagonist does not induce a biological effect per se (Baun, 2011). By examining the functionality of VPAC receptors, we can conclude that the expressions of important molecules of Th17 cells such as RORA, RORC or IL-17A are up-regulated by VIP through $\mathrm{VPAC}_{1}$ and $\mathrm{VPAC}_{2}$ receptors. Meanwhile, VIP exerts up-regulation of IL-23R, a crucial molecule for Th17 stabilization in the late stages of Th17 differentiation, through the VPAC 2 receptor. However, the $\mathrm{VPAC}_{1}$ receptor was shown to mediate STAT3 up-regulation, according to a previous study that describes the effect of VIP on STAT3 in human renal cell carcinoma (Vacas, 2012).

In conclusion, our results demonstrate that VIP may maintain the nonpathogenic/anti-inflammatory profile of human Th17 cells; increase their proliferation rate; and reduce the Th1 potential of these cells. In addition, Th17 differentiation induces a switch 
in VPAC receptor expression pattern. These results highlight a novel translational view in inflammation/autoimmune diseases, which adds new reasons to consider VIP as a therapeutic agent with great potential in the clinical setting.

\section{Acknowledgements}

This work was supported by the Fondo de Investigación Sanitaria, Instituto de Salud Carlos III (PI11/00195, PI12/00758 and RETICS RD08/0075, RD12/0009/0002) within VI PNDE I+D+I by FEDER funds from EU and S2010/BMD-2350 from Comunidad Autónoma de Madrid (CAM) and by grants from the ISCIII to RJ, and the FPI grants from Ministerio de Economía y Competitividad to SPG. Thank you to the Transfusion Centre of CAM and healthy donors for human cord blood samples.

\section{References}

Abad C, Juarranz Y, Martínez C, Arranz A, Rosignoli F, García-Gómez M, et al. (2005) cDNA array analysis of cytokines, chemokines and receptors envolved in the development of TNBSinduced colitis: homeostatic role of VIP. Inflamm Bowel Dis. 11:674-684.

Acosta-Rodriguez EV, Rivino L, Geginat J, Jarrossay D, Gattorno M, Lanzavecchia A, et al. (2007) Surface phenotype and antigenic specificity of human interleukin 17-producing T helper memory cells. Nat Immunol. 8:639-646.

Amadi-Obi A, Yu CR, Liu X, Mahdi RM, Clarke GL, Nussenblatt RB, et al. (2007) TH17 cells contribute to uveitis and seleritis and are expanded by IL-2 and inhibited by IL-27/STAT1. Nat Med. 13:711-718. 
Arranz A, Abad A, Juarranz Y, Leceta J, Martínez C, Gomariz RP. (2008) Vasoactive intestinal peptide as a healing mediator in Crohn's disease. Neuroimmunomodulation. 15:46-53.

Baun M, Hay-Schmidt A, Edvinsson L, Olesen J, Jansen-Olesen I. (2011) Pharmacological characterization and expression of VIP and PACAP receptors in isolated cranial arteries of the rat. Eur J Pharmacol. 670:186-194.

Beriou G, Brandshaw EM, Lozano E, Costantino CM, Hastings WD, Orban T, et al. (2010) TGF beta induces IL-9 production from human Th17 cells. J Immunol. 185:46-54.

Bi Y, Yang R. (2012) Direct and indirect regulatory mechanisms in TH17 cell differentiation and functions. Scand J Immuno. 75:543-552.

Calafat M, Larocca L, Roca V, Hauk V, Pregi N, Nessi A, et al. (2009) Vasoactive intestinal peptide inhibits TNF-alpha-induced apoptotic events in acinar cells from nonobese diabetic mice submandibular glands. Arthritis Res Ther. 11:R53.

Ceraudo E, Hierso R, Tan YV, Murail S, Rouyer-Fessard C, Nicole P, et al. (2012) Spatial proximity between the VPAC1 receptor and the amino terminus of agonist and antagonist peptides reveals distinct sites of interaction. FASEB J. 26:2060-2071.

Chen Z, O'Shea JJ.(2008) Regulation of IL17 production in human lymphocytes. Cytokine. 41:71-78.

Couvineau A, Laburthe M. (2012) VPAC receptors: structure, molecular pharmacology and interaction with accessory proteins. Br J Pharmacol. 166:42-50.

Cua DJ, Tato CM. (2010) Innate IL-17-producing cells: the sentinels of the immune system. Nat Rev Immunol. 10:479-489. 
Delgado M, Abad C, Martínez C, Leceta J, Gomariz RP. (2001) Vasoactive intestinal peptide prevents experimental arthritis by downregulating both autoimmune and inflammatory components of the disease. Nat Med. 7:563-568.

Delgado M, Martinez C, Johnson MC, Gomariz RP, Ganea D. (1996) Differential expression of vasoactive intestinal peptide receptors 1 and 2 (VIP-R1 and VIP-R2) mRNA in murine lymphocytes. J Neuroimmunol. 68:27-38.

Ding W, Manni M, Stohl LL, Zhou XK, Wagner JA, Granstein RD. ( 2012) Pituitary adenylate cyclise-activating polypeptide and vasoactive intestinal polypeptide bias Langerhans cell $\mathrm{Ag}$ presentation toward Th17 cells. Eur J Immunol. 4:901-911.

Dorsam GP, Benton K, Failing J, Batra S. (2011) Vasoactive intestinal peptide signalling axis in human leukemia. World J Biol Chem. 2:146-160.

Dorsam ST, Vomhof-DeKrey E, Hermann RJ, Haring JS, Van der Steen T, Wilkerson E et al. (2010) Identification of the early VIP-regulated transcriptome and its associated, interactome in resting and activated murine CD4 T cells. Mol Immunol. 47:1181-1194.

Ganjalikhani M, Ghaedi K, Ahdalib A, Hosseini M, Rezaei A. (2011) Optimization of human Th17 cell differentiation in vitro: evaluating different polarization factors. In vitro Cell Dev Biol Anim. 47:581-592.

Ghoreschi K, Laurence A, Yang XP, Hirahara K, O'Shea JJ. (2011) T helper 17 cell heterogeneity and pathogenicity in autoimmune disease. Trends Immunol. 39:395-401.

Gomariz RP, Gutiérrez-Cañas I, Arranz A, Carrión M, Juarranz Y, Leceta J, et al. (2010) Peptides targeting Toll-like receptor signalling pathways for novel immune therapeutics. Curr Pharm Des. 16:1063-1080. 
Gomariz RP, Juarranz Y, Abad C, Arranz A, Leceta J, Martínez C. (2006) VIP-PACAP system in immunity: new insights for multitarget theraphy. Ann N Y Acad Sci. 1070: 51-74.

Gourlet P, De Neef P, Cnudde J, Waelbroeck M, Robberecht P. (1997) In vitro properties of a high affinity selective antagonist of the VIP1 receptor. Peptides. 18:1555-1560.

Graeber KE, Olsen NJ. (2012) Th17 cell cytokine secretion profile in host defense and autoimmunity. Inflamm Res. 61:87-96.

Gutiérrez-Cañas I, Juarranz Y, Santiago B, Martínez C, Gomariz RP, Pablos JL, et al. (2008) Immunoregulatory properties of vasoactive intestinal peptide in human $\mathrm{T}$ cell subsets: implications for rheumatoid artritis. Brain Behav Immun. 22:312-317.

Harmar AJ, Fahrenkrug J, Gozes I, Laburthe M, May V, Pisegna JR, et al. (2012) Pharmacology and functions of receptors for vasoactive intestinal peptide and pituitary adenylate cyclaseactivating polypeptide: IUPHAR review 1. Br J Pharmacol. 166:4-17.

Hirahara K, Ghoreschi K, Laurence A, Yang XP, Kanno Y O’Shea JJ. (2010) Signal transduction pathways and transcriptional regulation in Th17 cell differentiation. Cytokine Growth Factor Rev. 21:425-434.

Hirota K, Ahlfors H, Duarte JH, Stockinger B. (2012) Regulation and function of innate and adaptive interleukin-17 producing cells. EMBO Rep. 13:113-120.

Jimeno R, Gomariz RP, Gutiérrez-Cañas I, Martínez C, Juarranz Y, Leceta J. (2010) New insights into the role of VIP on the ratio of T-cell subsets during the development of autoimmune diabetes. Immuno Cell Biol. 88:734-745. 
Jimeno R, Leceta J, Martínez C, Gutiérrez-Cañas I, Pérez-García S, Carrión M, et al. (2011) Effect of VIP on the balance between cytokines and master regulators of activated helper T cells. Immunol Cell Biol. 90:178-186.

Juarranz Y, Gutiérrez-Cañas I, Santiago B, Carrión M, Pablos JL, Gomariz RP. (2008) Differential expression of vasoactive intestinal peptide and its functional receptors in human osteoarthritic and rheumatoid synovial fibroblasts. Arthritis Rheum. 58:1086-1095.

Korn T, Bettelli E, Oukka M, Kuchroo VK. (2009) IL-17 and Th17 Cells. Annu Rev Immunol. 27:485-517.

Leceta J, Gomariz RP, Martinez C, Carrión M, Arranz A, Juarranz Y. (2007) Vasoactive intestinal peptide regulates Th17 function in autoimmune inflammation. Neuroimmunomodulation 14:134-138.

Lee Y, Awasthi A, Yosef N, Quintana FJ, Xiao S, Peters A, et al. (2012) Induction and molecular signature of pathogenic TH17 cells. Nat Immunol. 13:991-999.

Lee YK, Turner H, Maynard CL, Oliver JR, Chen D, Elson CO, et al. (2008) Late developmental plasticity in the T helper 17 lineage. Immunity. 30:92-107.

Lexberg MH, Taubner A, Albrecht I, Lepenies I, Richter A, Kamradt T, et al. (2010) IFNY and IL12 synergize to convert in vivo generated Th17 into Th1/Th17 cells. Eur J Immunol. 40:301727.

Lodde BM, Mineshiba F, Wang J, Cotrim AP, Afione S, Tak PP, et al. (2006) Effect of human vasoactive intestinal peptide gene transfer in a murine model of Sjogren's syndrome. Ann Rheum Dis.65:195-200. 
Marwaha AK, Leung NJ, McMurchy AN, Leving MK. (2012) TH17 Cells in Autoimmunity and Immunodeficiency: Protective or Pathogenic? Front Immunol. 3:129.

McGeachy MJ, Bak-Jensen KS, Chen Y, Tato CM, Blumenschein W, McClanahan T, et al. (2007) TGF-beta and IL-6 drive the production of IL-17 and IL-10 by T cells and restrain T(H)17 cell-mediated pathology. Nat Immunol. 8:1390-1397.

Murphy KM, Stockinger B. (2010) Effector T cell plasticity: flexibility in the face of changing circumstances. Nat Immunol. 11:674-680.

O'Shea JJ, Paul WE. (2010) Mechanisms underlying lineage commitment and plasticity of helper CD4+ T cells. Science. 327:1098-1102.

Santarlasci V, Maggi L, Capone M, Querci V, Beltrame L, Cavalieri D, et al. (2012) Rarity of Human T Helper 17 Cells Is due to Retinoic Acid Orphan Receptor-Dependent Mechanisms that Limit Their Expansion. Immunity. 36:201-214.

Smalley SG, Barrow PA, Foster N. (2009) Immunomodulation of innate immune responses by vasoactive intestinal peptide (VIP): its therapeutic potential in inflammatory disease. Clin Exp Immunol. 157:225-234.

Sundrud MS, Trivigno C. (2013) Identity crisis of Th17 cells: Many forms, many functions, many questions. Semin Immunol. 25:263-272.

Vacas E, Fernández-Martínez AB, Bajo AM, Sánchez-Chapado M, Schally AV, Prieto JC, et al. (2012) Vasoactive intestinal peptide (VIP) inhibits human renal cell carcinoma proliferation. Biochim Biophys Acta. 1823:1676-1685. 
Veldhoen M, Hirota K, Westendorf AM, Buer J, Dumoutier L, Renauld JC, et al. (2008) The aryl hydrocarbon receptor links TH17-cell-mediated autoimmunity to environmental toxins. Nature. 453:106-109.

Vomhof-Dekrey EE, Dorsam GP. (2008) Stimulatory and suppressive signal transduction regulates vasoactive intestinal peptide receptor-1 (VPAC-1) in primary mouse CD4 T cells. Brain Behav Immun. 22:1024-1031.

Yadav M, Rosenbaum J, Goetzl EJ. (2008) Cutting edge: Vasoactive intestinal peptide (VIP) induces differentiation of Th17 cells with a distinctive cytokine profile. J Immunol. 180:27722776.

Yang XO, Pappu BP, Nurieva R, Akimzhanov A, Kang HS, Chung Y, et al. (2008) T helper 17 lineage differentiation is programmed by orphan nuclear receptors ROR alpha and ROR gamma. Immunity. 28:29-39.

Zhu J, Paul WE. (2008) CD4 T cells: fates, functions and faults. Blood. 112:1557-1569.

Zhu J, Paul WE. (2010) Peripheral CD4+ T-cell differentiation regulated by networks of cytokines and transcription factors. Immunol Rev. 238:247-262.

Zuñiga LA, Jain R, Haines C, Cua DJ. (2013) Th17 cell development from the cradle to the grave. Immunol Rev. 252:78-88. 


\section{Figure Legends}

Figure 1. Cytokine profile and cytokine receptor expressed by human Th17- and VIP/Th17polarized cells. (A) Protein expression of IL-17A, IL-21, IL-22, IFNY, IL-2, IL-10 and IL-9 was analyzed in culture supernatants by ELISA. Values were corrected considering the final volume of supernatants and the number of viable cells of each sample. (B) mRNA expression of IL-21R, IL-23R and IL-12Rß2 was determined by real-time PCR on day 7. Data were analyzed normalizing with $\beta$-Actin mRNA expression and compared with the mRNA expression of $C D 4^{+} C D 45 R A^{+} T$ cells (which was set at 1 ). Data are the mean \pm SEM of six different cultures, performed in duplicate or triplicate. ${ }^{*} P<0.05, * * P<0.01, * * * P<0.001$ non-polarized cells versus the other conditions, and \# $P<0.05$, \#\#\# $P<0.001$ Th17-polarized versus VIP/Th17-polarized.

Figure 2. Transcription factors expressed by human Th17- and VIP/Th17-polarized cells. mRNA expression of RORC, RORA, AhR, STAT3, Foxp3 and Tbx21 was determined by realtime PCR on day 7. Data were analyzed normalizing with $\beta$-Actin mRNA expression and compared with the mRNA expression of $C D 4^{+} C D 45 R A^{+}$T cells (which was set at 1 ). Data are the mean \pm SEM of six different cultures, performed in duplicate or triplicate. ${ }^{*} P<0.05, * *$ $P<0.01, * * * P<0.001$ non-polarized cells versus the other conditions, and $\# P<0.05, \# \#$ P<0.01, \#\#\# P<0.001 Th17-polarized versus VIP/Th17-polarized.

Figure 3. Relationships between mRNA expression of several cytokines and master regulators suggest a non-pathogenic Th17 phenotype. Correlation between mRNA expression of IL-10 and IL-17A, IL-9 and IL-17A, IL-21 and IL-17A, IL-2 and IL-17A, and RORC and IL-22 were determined by real-time PCR on day 7 of culture after PMA and ionomycin stimulation for six hours. Data were analyzed normalizing with $\beta$-Actin mRNA expression and 
compared with the mRNA expression of $\mathrm{CD}^{+} \mathrm{CD} 45 \mathrm{RA}^{+} \mathrm{T}$ cells (which was set at 1 ). Data are the mean \pm SEM of six different cultures performed in triplicate. Pearson's coefficients $(r)$ are shown.

Figure 4. Relationships between specific cytokines and master regulators for Th17 and Th1 subsets under VIP influence. (A) Correlation between mRNA expression of IFNY and IL-17A or Tbx21 and RORC was determined by real-time PCR on day 7 of culture after PMA and ionomycin stimulation for six hours. Data were analyzed normalizing with $\beta$-Actin mRNA expression and compared with the mRNA expression of $C D 4^{+} C D 45 R A^{+} T$ cells (which was set at 1). Data are the mean \pm SEM of six different cultures performed in triplicate. Pearson's coefficients ( $r$ ) are shown. (B) T-bet and RORC expression was determined by flow cytometry analysis. After 7 days of culture, cells were labelled with Alexa Fluor 488-conjugated T-bet and allophycocyanin-conjugated RORC. Figure shows a dot plot analysis indicating T-bet expression versus RORC expression in Th17-polarized and VIP/Th17-polarized cells. One representative experiment of three is shown.

Figure 5. Influence of VIP on proliferation and homing capacity of Th17-polarized cells. (A) Cell proliferation rate and cell viability were tested in the different cell populations. A colorimetric method based on BrdU incorporation into DNA during cell division was used in the cultures on day 4 and 7. According to the blank and background values, absorbance data were converted to percentages considering the mean of absorbance data of Th17-polarized cells of each sample as $100 \%$. Final results correspond to the mean \pm SEM of three different cultures. ${ }^{*} P<0.05, * * * P<0.001$ non-polarized cells versus the other conditions and $\# P<0.05$, \#\#\# $P<0.001$ Th17-polarized versus VIP/Th17-polarized. Viability of cells was determined by trypan blue dye exclusion assay on day 7 of culture in the different cell populations. Cell 
viability was calculated as the relationship between the number of viable cells on day 7 and the total number of cells cultured. Values were adjusted considering the number of wells cultured for each sample. (B) Th17-polarized cells proliferation was also tested by flow cytometry analysis studying Ki67 and RORC expression. After seven days of culture, cells were labelled with Brilliant Violet 711-conjugated Ki67 and allophycocyanin-conjugated RORC. Figure shows a dot plot analysis indicating Ki67 expression versus RORC expression and a histogram analysis indicating Ki67 expression. One representative example of three is shown. (C) Homing capacity of Th17-polarized cells was studied analyzing CCR6 expression by flow cytometry analysis. After seven days of culture, cells were labelled with phycoerythrin-conjugated CCR6 and allophycocyanin-conjugated RORC. Figure shows a dot plot analysis indicating CCR6 expression versus RORC expression. One representative experiment of three is shown.

Figure 6. Switch in the expression pattern of VPAC receptors during human Th17 differentiation. (A) mRNA expression of $\mathrm{VPAC}_{1}$ and $\mathrm{VPAC}_{2}$ was determined by real-time $\mathrm{PCR}$ on day 0 for $\mathrm{CD}^{+} \mathrm{CD} 4 \mathrm{RA}^{+} \mathrm{T}$ cells and on day 7 of culture after PMA and ionomycin stimulation for six hours for non-polarized cells, Th17-polarized and VIP/Th17-polarized cells. Data were analyzed normalizing with $\beta$-Actin mRNA expression and compared with $\mathrm{VPAC}_{2}$ mRNA expression of non-polarized cells (which was set at 1). Individual mRNA expression and the ratio between mRNA expression of $\mathrm{VPAC}_{1}$ and $\mathrm{VPAC}_{2}$ are shown. Data are the mean \pm SEM of five different cultures performed in triplicate. $* * P<0.01, * * * \quad P<0.001$ $\mathrm{CD}^{+}{ }^{+} \mathrm{CD} 45 \mathrm{RA}^{+} \mathrm{T}$ cells versus the other conditions, \#\#\# $P<0.001$ non-polarized cells versus Th17-polarized cells and $\delta \delta \delta P<0.001$ Th17-polarized versus VIP/Th17-polarized. (B) Protein expression of $\mathrm{VPAC}_{1}$ and $\mathrm{VPAC}_{2}$ receptors was analyzed by immunofluorescence staining in $\mathrm{CD}^{+} \mathrm{CD} 4 \mathrm{RA}^{+} \mathrm{T}$ cells on day 0 and Th17-polarized cells on day 7. Nuclei were counterstained 
with Hoechst (blue) and receptors were stained with Alexa Fluor 488-conjugated secondary antibody (green) and Alexa Fluor 594-conjugated secondary antibody (red) for $\mathrm{VPAC}_{1}$ and $\mathrm{VPAC}_{2}$, respectively. One representative example of three is shown.

\section{Figure 7. Effect of specific agonists and antagonist for VPAC receptors during Th17} polarization. mRNA expression of IL-17A, IL-23R, RORC, RORA and STAT3 was determined by real-time PCR on day 7 of culture. Different conditions for Th17-polarized cells were performed. Data were analyzed normalizing with $\beta$-Actin mRNA expression and compared with mRNA expression of non-polarized cells (which was set at 1). Data for Th17-polarized cells was referred as $100 \%$ and the other mRNA expression calculated as a percentage with respect to Th17-polarized cells. Data are the mean \pm SEM of three different cultures performed in triplicate. ${ }^{*} P<0.05, * * P<0.01, * * * P<0.001$, Th17-polarized cells versus the other conditions. \# $P<0.05, \# \# P<0.01, \# \# \# P<0.001$, VIP/Th17-polarized cells versus VIP/Th17-polarized cells + VPAC $_{1}$ antagonist cells.

Figure 8. Schematic representation of VIP effect on human Th17-polarized cells from naïve T cells. (A) The presence of VIP during human Th17 differentiation maintains Th17 commitment significantly enhancing IL-23R, RORC, RORA and STAT3 expression; reduces the Th1 potential of Th17 cells; and increases the Th17 proliferation rate (B) VIP presence during human Th17 polarization up-regulates the expression of several molecules through its receptors $\mathrm{VPAC}_{1}$ and $\mathrm{VPAC}_{2}$. RORA, RORC or IL-17A expression are up-regulated by VIP through $\mathrm{VPAC}_{1}$ and $\mathrm{VPAC}_{2}$ receptors; IL-23R expression is up-regulated by VIP through the $\mathrm{VPAC}_{2}$ receptor; and STAT3 expression is up-regulated by VIP through VPAC . 

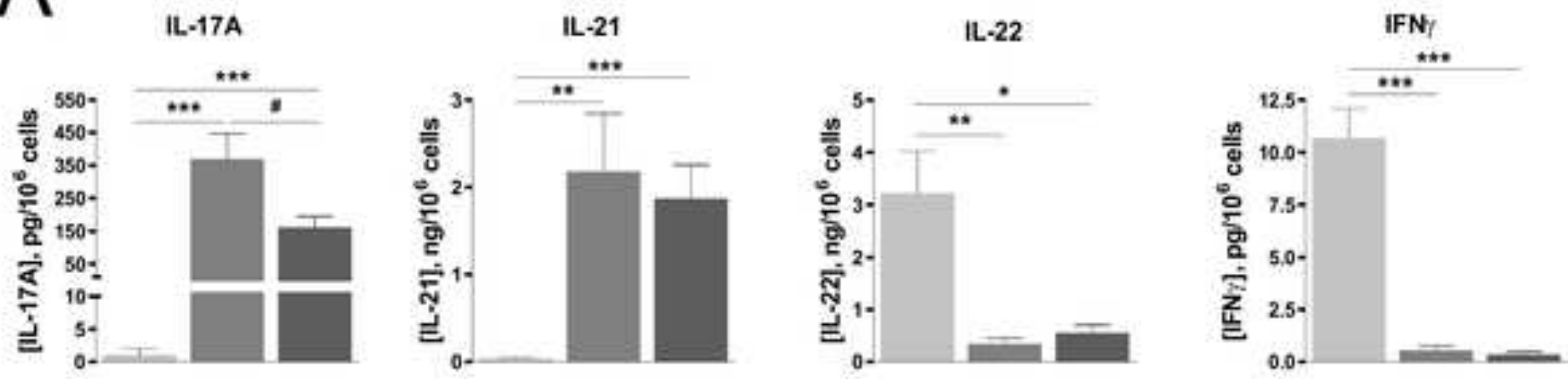

IL-2

IL-10

IL. -9
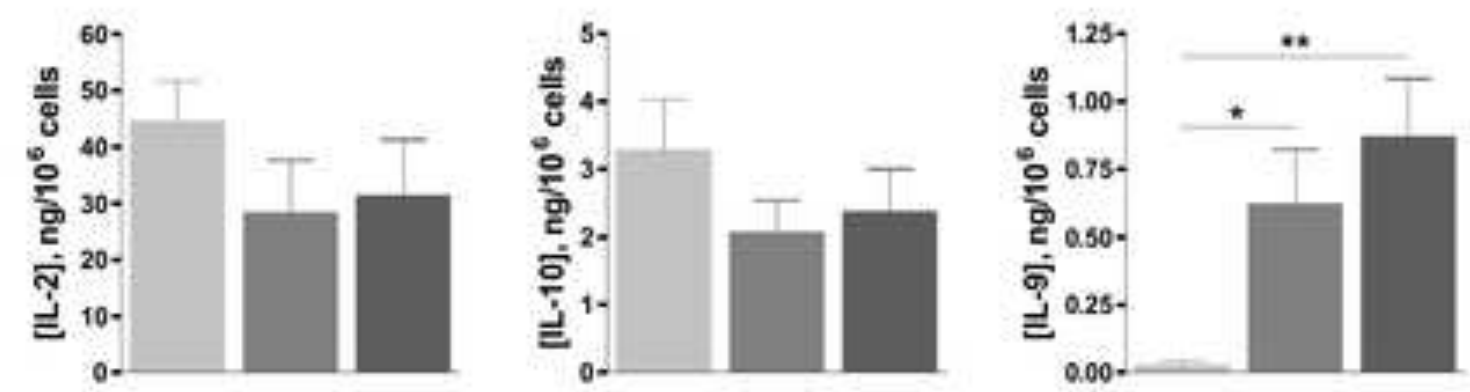

Non-polarized Th cells

Th17-polarized cells

VIP/Th17-polanized cells

B

IL-21R

IL-23R

IL-12RP2
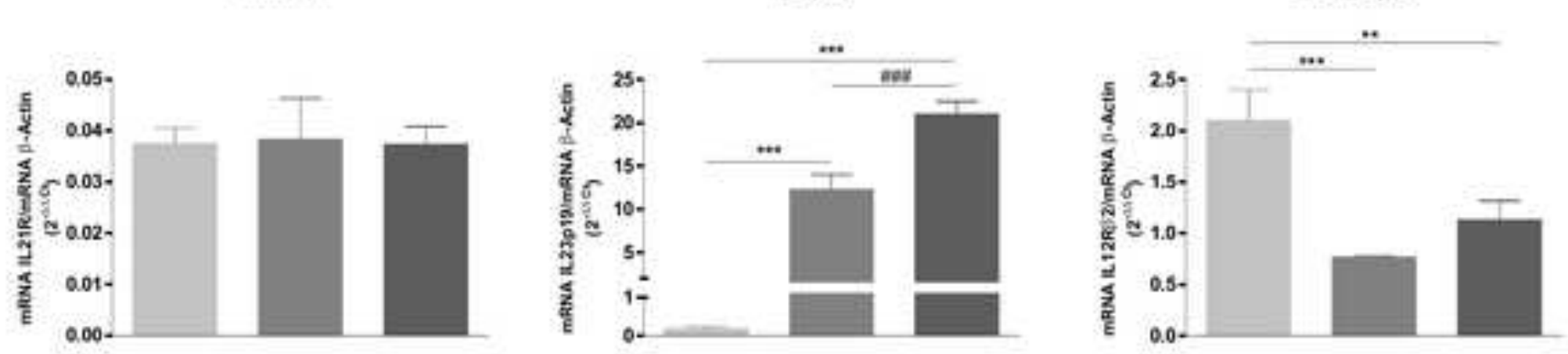

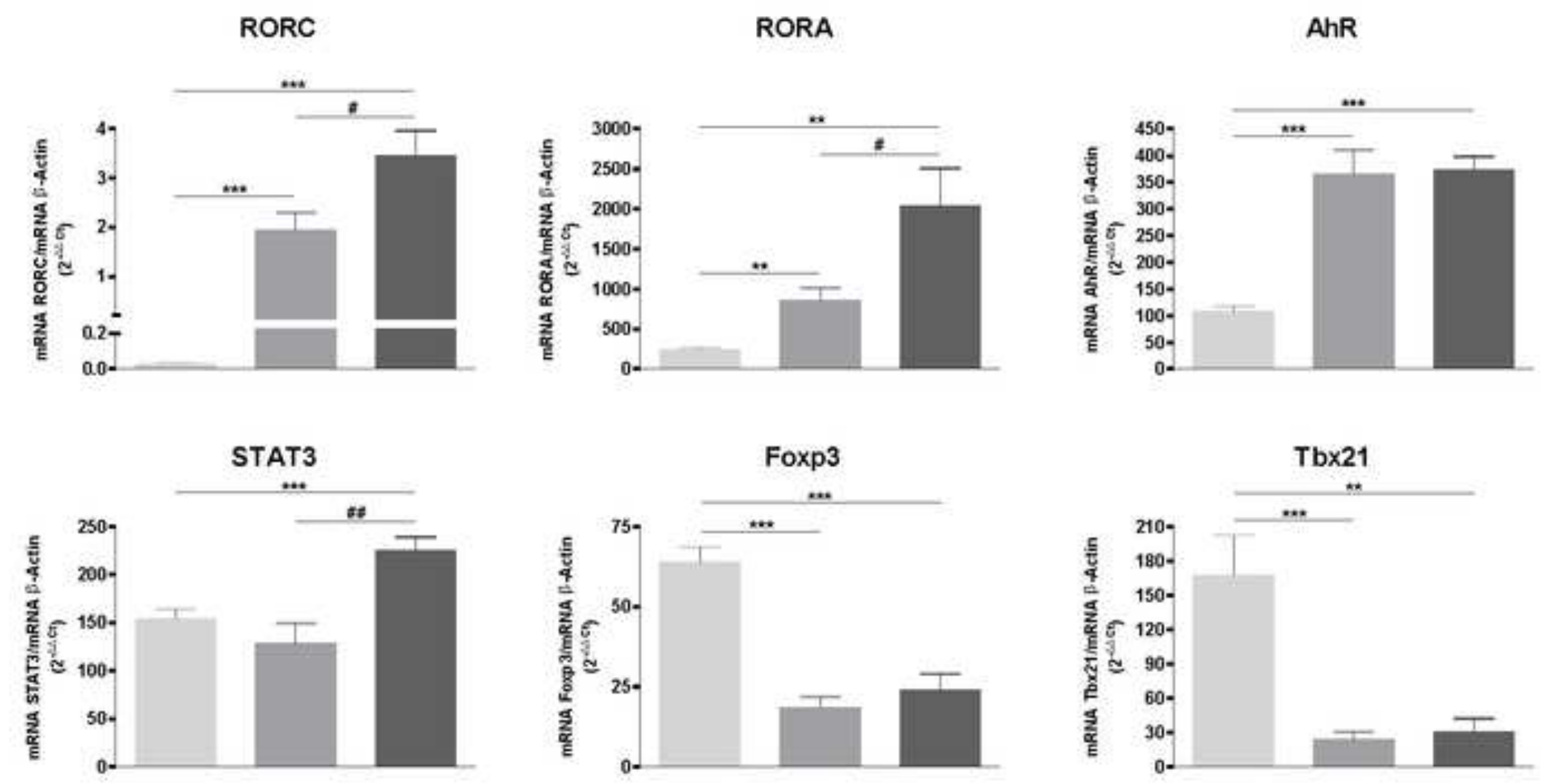

Non-polarized Th cells

Th17-polarized cells

— VIP/Th17-polarized cells 
Figure 3

Click here to download high resolution image

\section{IL-10/L-17 correlation}

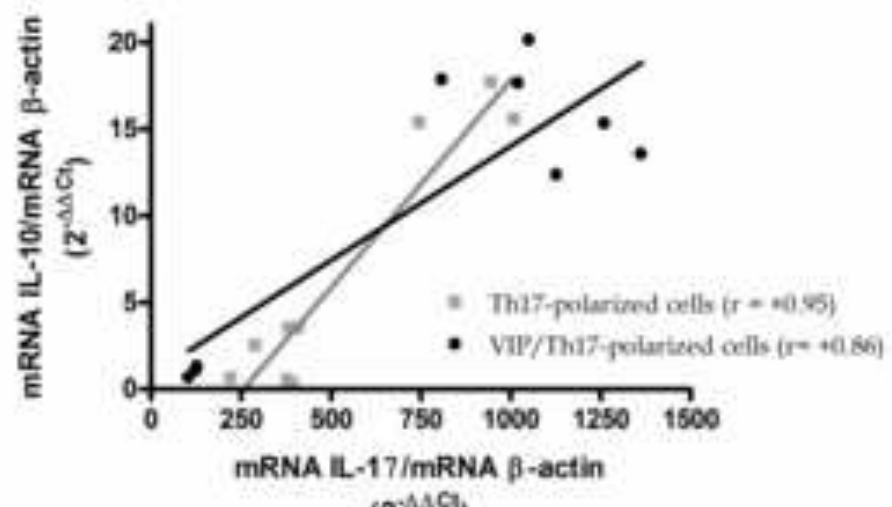

It-9AL-17 cocrelation
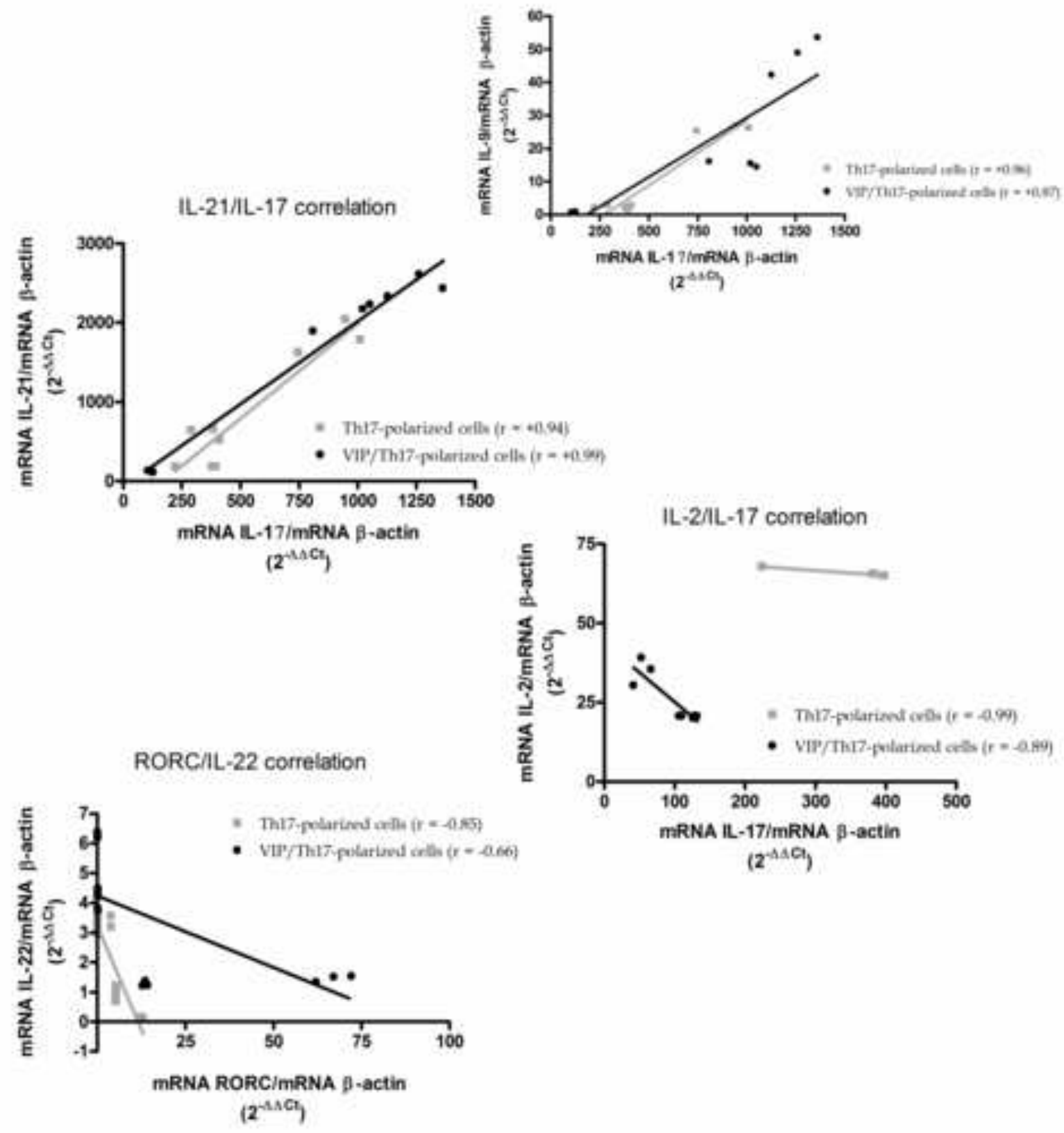

IL-2/L-17 correlation

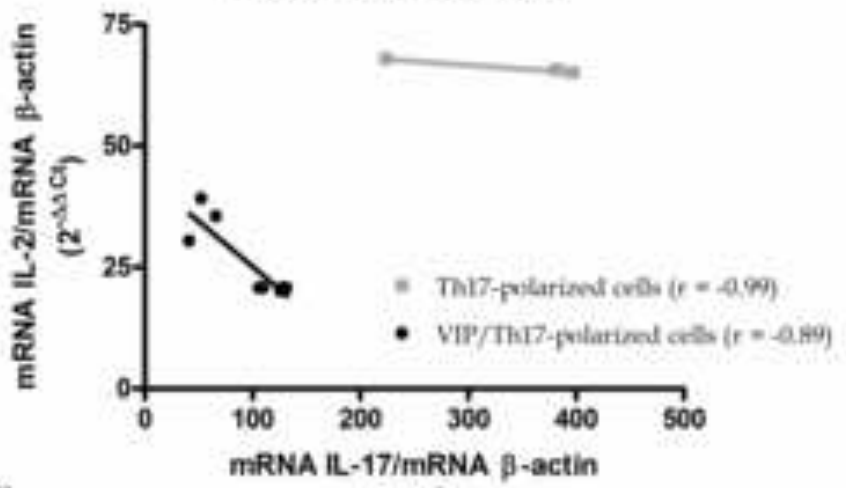

$\left(2^{-A \Delta a}\right)$

$$
\left(2^{-1 A C)}\right)
$$



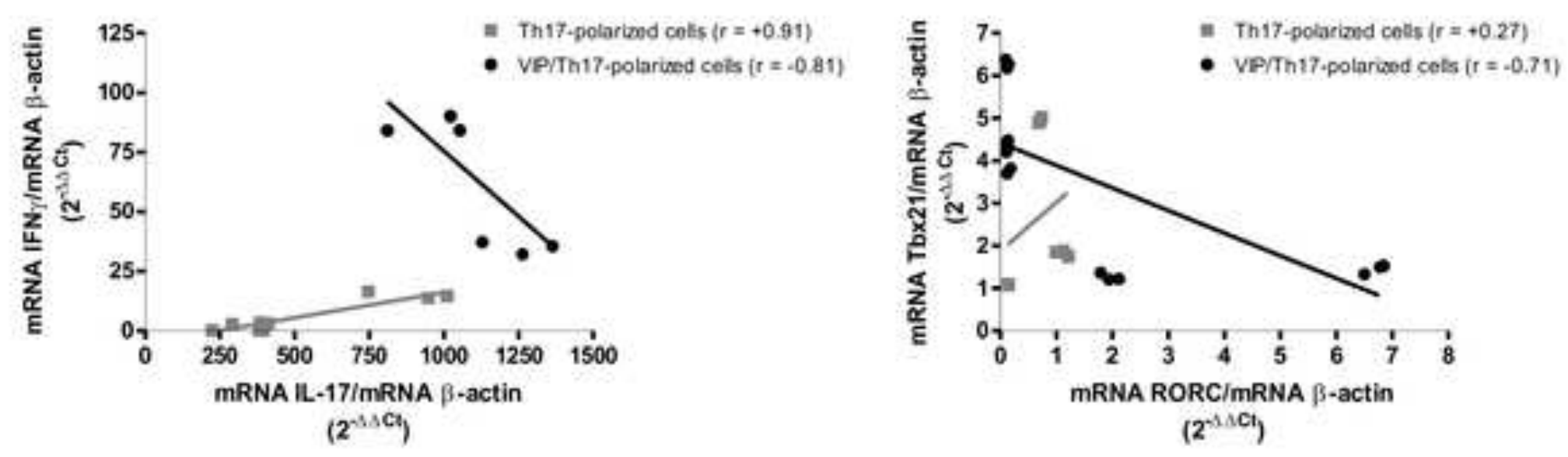

B
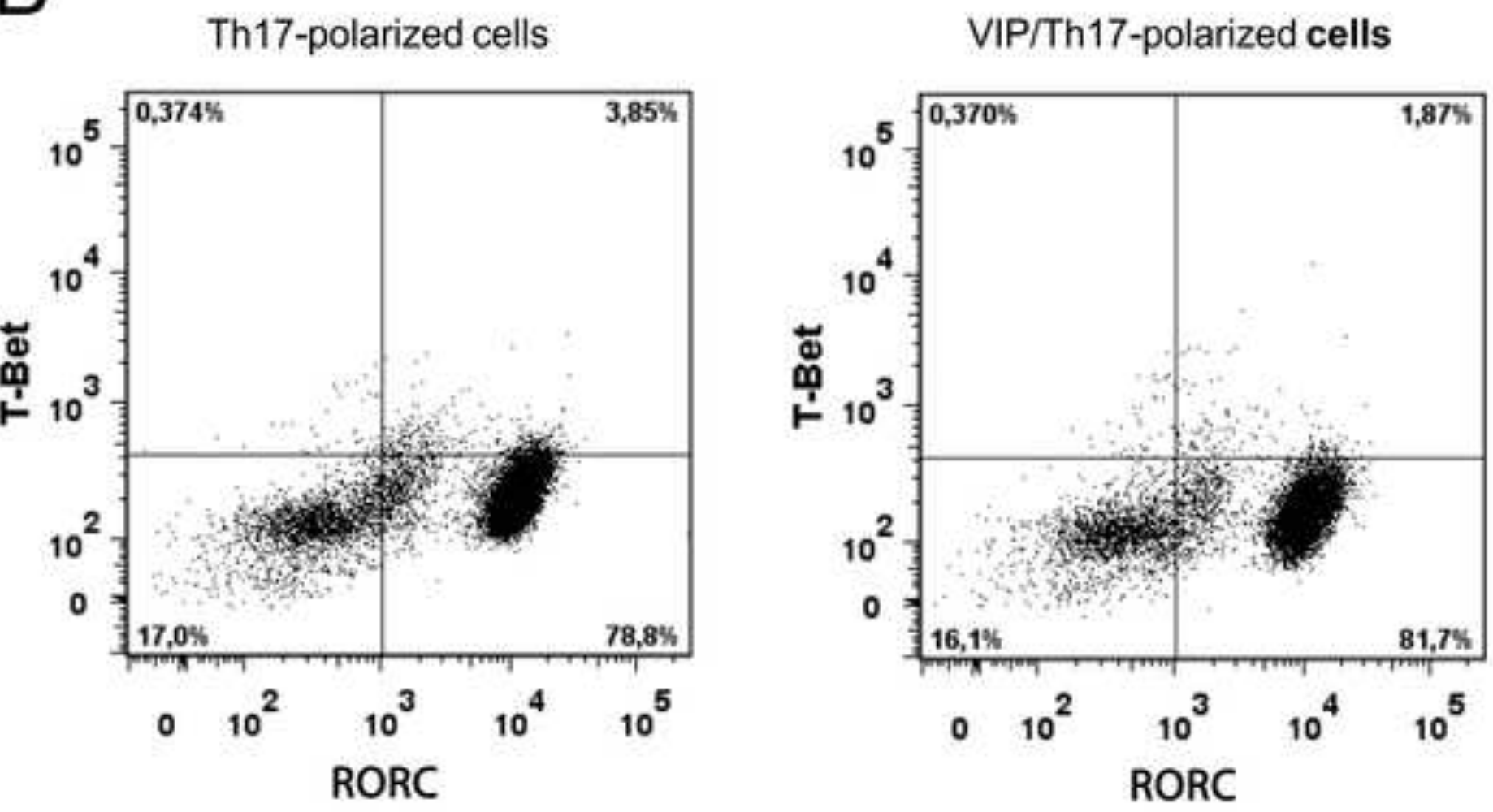
A Cell proliferation

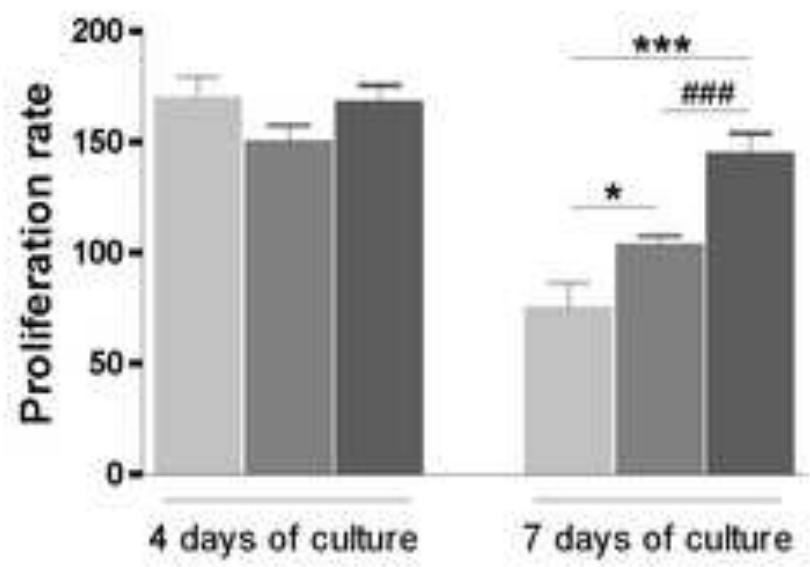

\section{Cell viability}

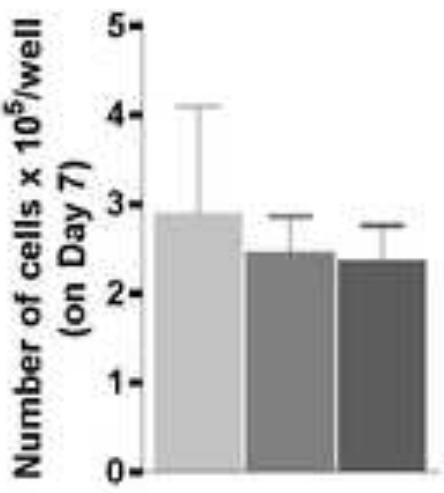

Non-polarized Th cells

Th17-polarized cels

VIP/Th17 polarized cells

B
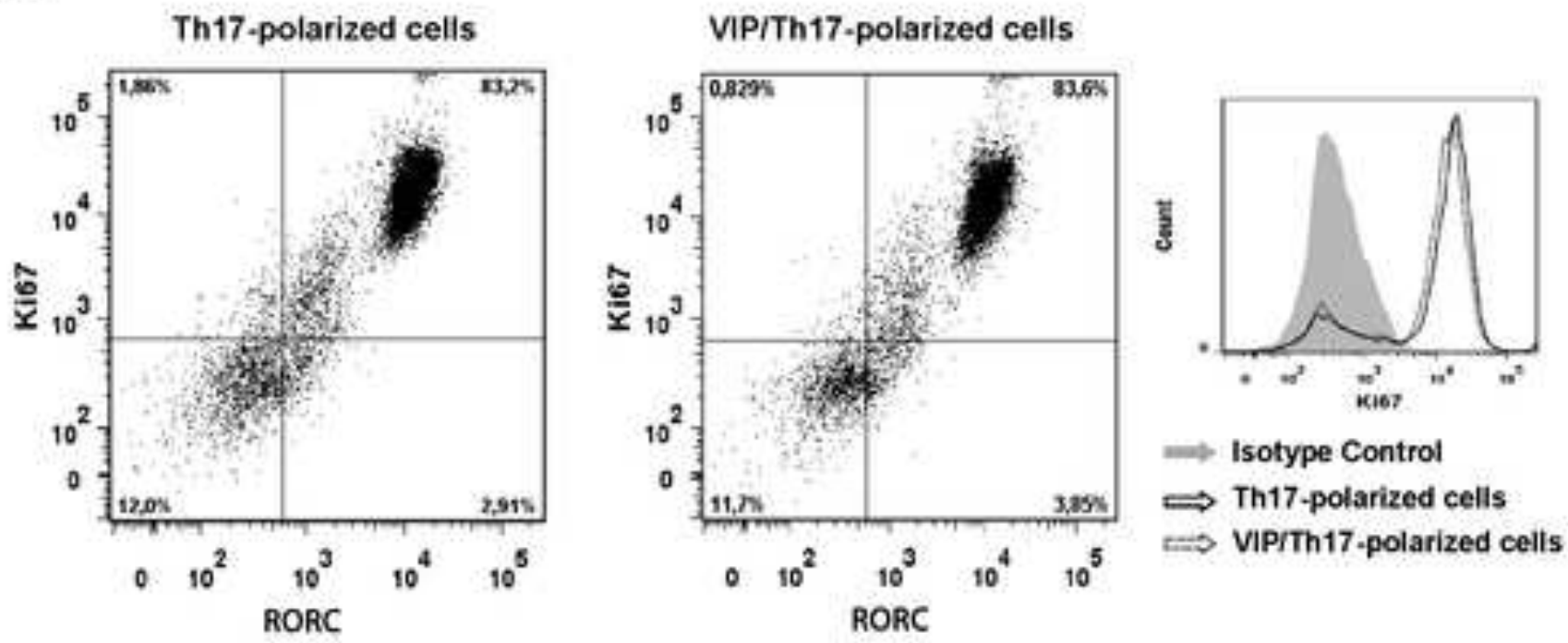

$\mathcal{C}$
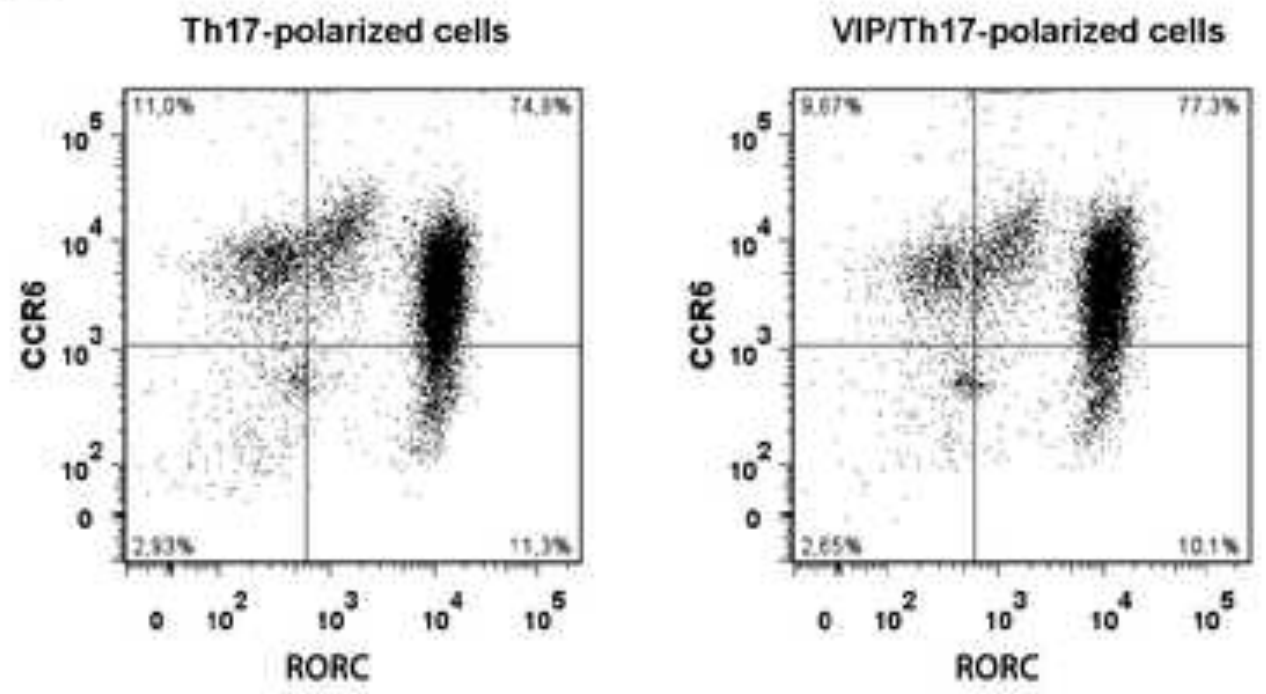
Click here to download high resolution image

A
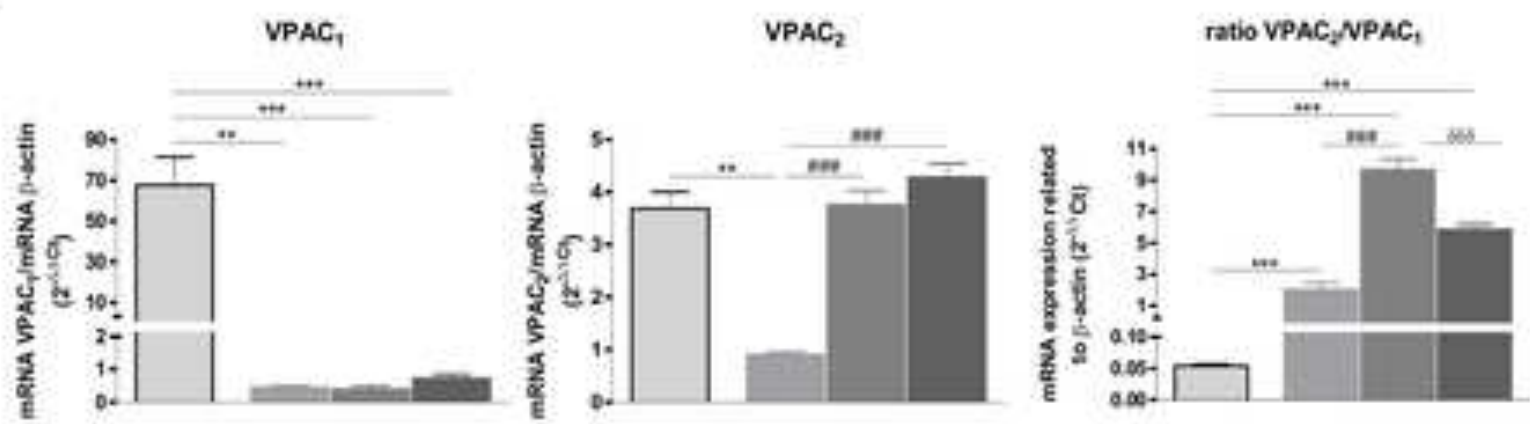

\section{CD4CD45RA T cells}

Non-polarized Th cells

B

CDACD45RA T cells

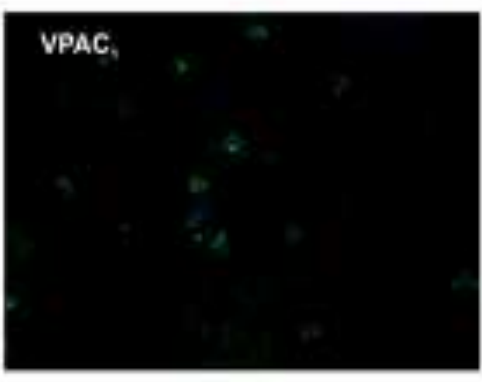

Th17-polarized cells

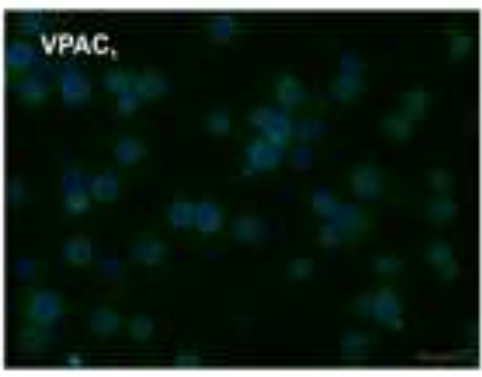

\section{VPAC,}

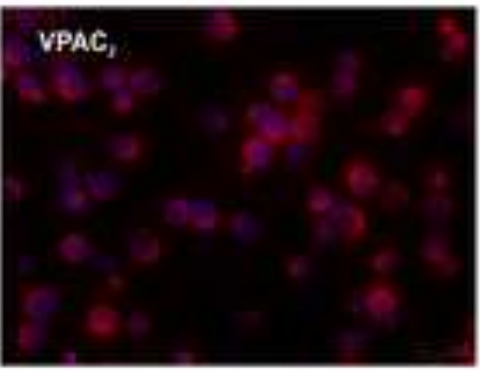

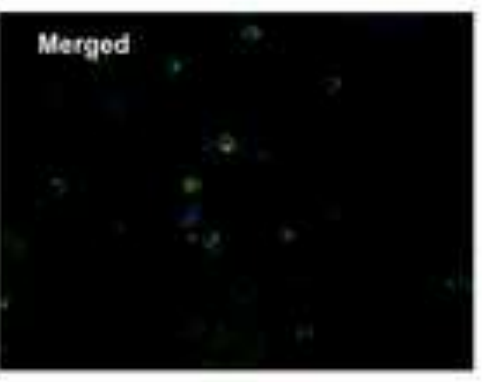

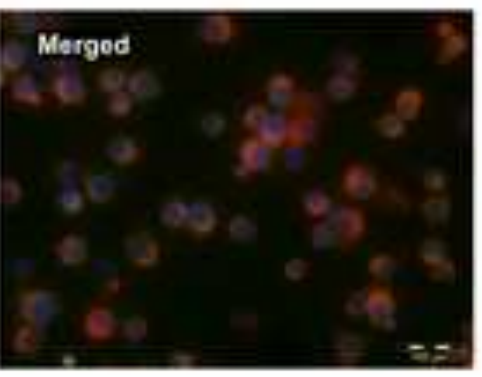



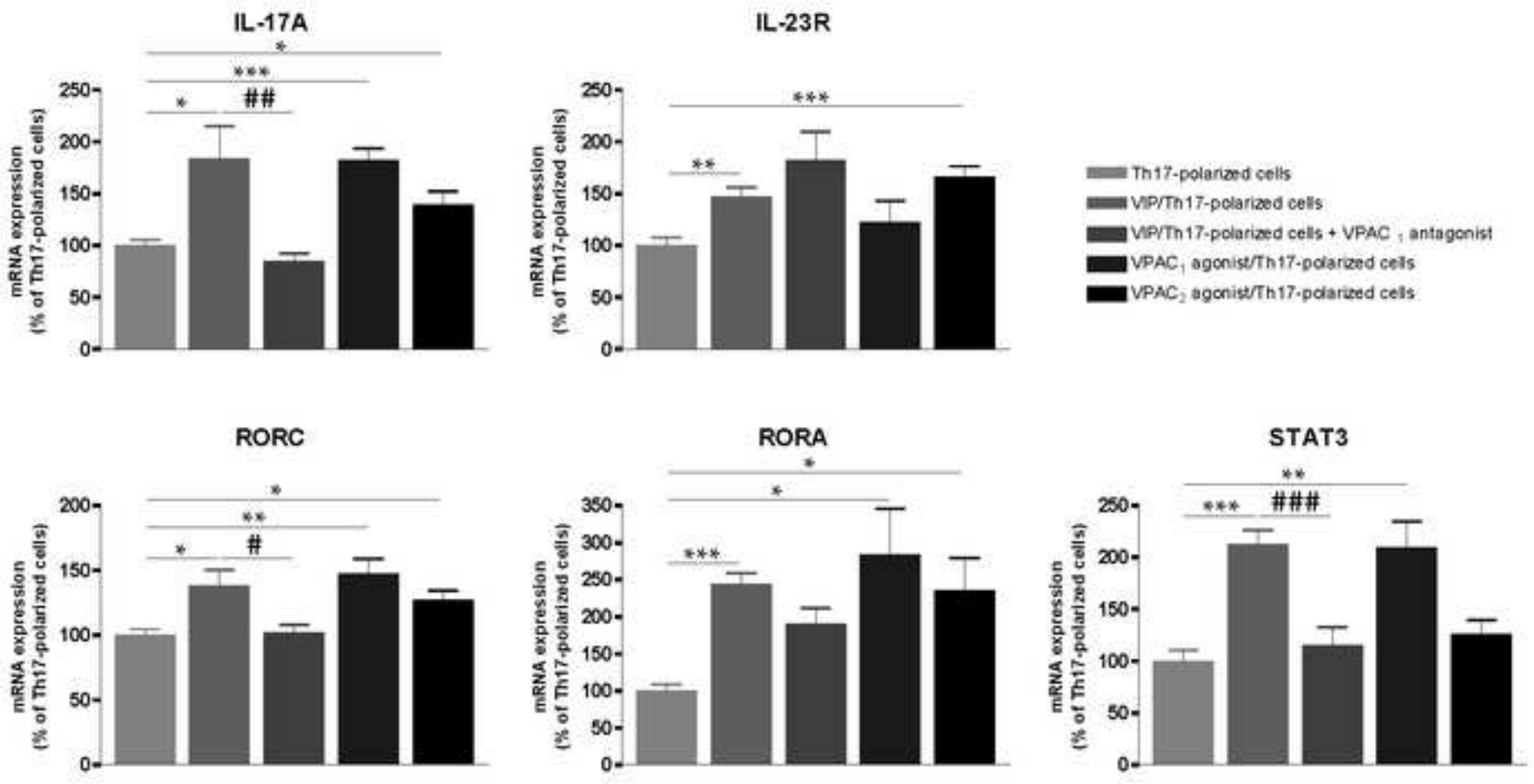
Click here to download high resolution image
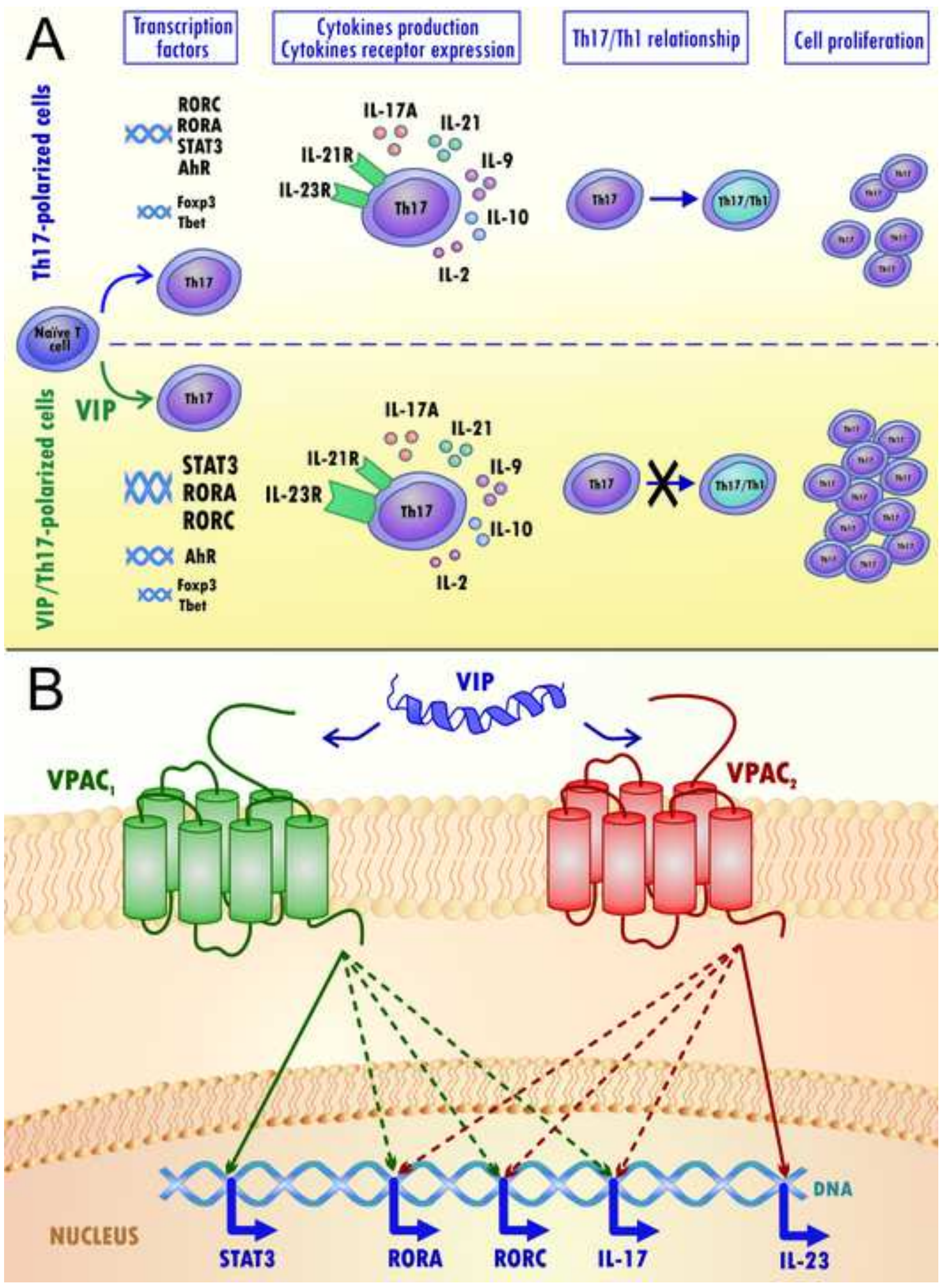


\section{Table 1: Genes analysed by semi-quantitative real-time Polymerase Chain}

Reaction. Method, gene, genebank accession number, sequence position or assay location and sequence or assay ID for each primer used in the study are showed.

\begin{tabular}{|c|c|c|c|c|}
\hline Method & Gene & $\begin{array}{c}\text { GenBank } \\
\text { accession no. }\end{array}$ & $\begin{array}{c}\text { Sequence } \\
\text { position/Assay location } \\
\text { (TaqMan®) }\end{array}$ & Sequence/Assay ID (TaqMan $\left.{ }^{\circledR}\right)$ \\
\hline SYBR $\circledast$ Green & $\beta$-actin & E00829 & $1435-1535$ & $\begin{array}{l}\text { Forward: 5'-AGAAGGATTCCTATGTGGGCG-3' } \\
\text { Reverse: 5'-CATGTCGTCCCAGTTGGTGAC-3' }\end{array}$ \\
\hline SYBR® Green & IL-22 & NM_020525 & $256-368$ & $\begin{array}{l}\text { Forward: 5'-ACAACACAGACGTTCGTCTCATTG-3' } \\
\text { Reverse: 5'-GAACAGCACTTCTTCAAGGGTGA-3' }\end{array}$ \\
\hline TaqMan® & IL-21R & NM_181079.3 & 275 & Hs00222310_m1 \\
\hline TaqMan® & IL-23R & NM_144701.2 & 1037 & Hs00332759_m1 \\
\hline TaqMan® & IL-12Rß2 & NM_001559.2 & 1900 & Hs00155486_m1 \\
\hline TaqMan® & RORC & NM_005060.3 & 182 & Hs00172860_m1 \\
\hline TaqMan $\circledast$ & RORA & NM_002943.3 & 1173 & Hs00536545_m1 \\
\hline TaqMan $®$ & AhR & NM_001621.4 & 1318 & Hs00169233_m1 \\
\hline TaqMan® & STAT3 & NM_003150.3 & 488 & Hs01047580_m1 \\
\hline TaqMan $\circledast$ & Foxp3 & NM_014009.3 & 1004 & Hs01085834_m1 \\
\hline TaqMan® & Tbx21 & NM_013351.1 & 707 & Hs00203436_m1 \\
\hline TaqMan® & IL-17A & NM_002190.2 & 279 & Hs00174383_m1 \\
\hline TaqMan ${ }^{\circledR}$ & IL-10 & NM_000572.2 & 510 & Hs00961622_m1 \\
\hline TaqMan® & IL-9 & NM_000590.1 & 325 & Hs00914237_m1 \\
\hline TaqMan® & IL-21 & NM_021803.3 & 406 & Hs00222327_m1 \\
\hline TaqMan® & IL-2 & NM_000586.3 & 267 & Hs00174114_m1 \\
\hline TaqMan® & IFNY & NM_000619.2 & 495 & Hs00989291_m1 \\
\hline TaqMan® & VPAC $_{1}$ & NM_004624.3 & 306 & Hs00270351_m1 \\
\hline TaqMan ${ }^{\circledR}$ & $\mathrm{VPAC}_{2}$ & NM_003382.4 & 644 & Hs00173643_m1 \\
\hline TaqMan® & $\beta$-actin & NM_001101.3 & 54 & Hs03023943_g1 \\
\hline
\end{tabular}

